\title{
Platelet-activating factor induces cell cycle arrest and disrupts the DNA damage response in mast cells
}

\author{
N Puebla-Osorio ${ }^{1}$, E Damiani ${ }^{2}$, L Bover ${ }^{1}$ and SE Ullrich ${ }^{*, 1,3}$
}

Platelet-activating factor (PAF) is a potent phospholipid modulator of inflammation that has diverse physiological and pathological functions. Previously, we demonstrated that PAF has an essential role in ultraviolet (UV)-induced immunosuppression and reduces the repair of damaged DNA, suggesting that UV-induced PAF is contributing to skin cancer initiation by inducing immune suppression and also affecting a proper DNA damage response. The exact role of PAF in modulating cell proliferation, differentiation or transformation is unclear. Here, we investigated the mechanism(s) by which PAF affects the cell cycle and impairs early DNA damage response. PAF arrests proliferation in transformed and nontransformed human mast cells by reducing the expression of cyclin-B1 and promoting the expression of p21. PAF-treated cells show a dose-dependent cell cycle arrest mainly at G2-M, and a decrease in the DNA damage response elements MCPH1/BRIT-1 and ataxia telangiectasia and rad related (ATR). In addition, PAF disrupts the localization of $p$-ataxia telangiectasia mutated (p-ATM), and phosphorylated-ataxia telangiectasia and rad related ( $p$-ATR) at the site of DNA damage. Whereas the potent effect on cell cycle arrest may imply a tumor suppressor activity for PAF, the impairment of proper DNA damage response might implicate PAF as a tumor promoter. The outcome of these diverse effects may be dependent on specific cues in the microenvironment.

Cell Death and Disease (2015) 6, e1745; doi:10.1038/cddis.2015.115; published online 7 May 2015

Ultraviolet (UV)-mediated immunosuppression poses a major risk for skin cancer induction, ${ }^{1,2}$ and many have reported that an essential mediator in this process is UV-induced platelet-activating factor (PAF; 1-alkyl-2-acetyl-sn-glycero-3phosphocholine). ${ }^{3-5}$ PAF is a phospholipid, first discovered as a secreted component by activated innate immune cells, 6,7 that mediates its activity by binding to a G-protein-coupled receptor. ${ }^{8}$ It is involved in a variety of mechanisms including the release of histamine in activated leukocytes, ${ }^{9-11}$ anaphylaxis, and phagocytosis. ${ }^{12}$

Exposure to low doses of UV radiation activates PAF release by keratinocytes, ${ }^{13,14}$ so it is likely that most of the population is regularly exposed to keratinocyte-derived PAF. In previous studies we showed that PAF upregulates both CXCR4 on mast cells and its ligand (CXCL12) on draining lymph node cells, promoting the migration of dermal mast cells from inflamed skin to the lymph nodes. ${ }^{15}$ Mast cells that reach the draining lymph nodes activate immune suppression by releasing interleukin $10 .^{16}$ Blocking mast cell migration by using a CXCR4 antagonist, AMD3100, blocks UV-induced immune suppression and the induction of skin cancer. ${ }^{15,17}$ No immune suppression is noted when PAF receptor-deficient mice $\left(\right.$ PAFR $^{-/-}$) are exposed to UV radiation, ${ }^{4,5}$ nor can one reconstitute immune suppression when $\mathrm{PAFR}^{-/}$mast cells are used to reconstitute mast cell-deficient mice. ${ }^{18} \mathrm{PAF}$ also has a critical role in skin cancer induction and progression, ${ }^{19,20}$ and this may reflect its capacity to both induce immune suppression and hamper DNA repair. ${ }^{21}$

Hanahan and Weinberg recognized the important roles inflammation and immune evasion play in the initiation of cancer. ${ }^{22}$ UV-induced PAF by activating immune suppression, retarding DNA repair and activating inflammation clearly constitutes an important hallmark for cancer induction. Supporting this idea is the observation that PAF is involved in a variety of other cancers besides skin cancer. ${ }^{23-27}$ Although we previously demonstrated that PAF suppresses the rate of DNA repair in vivo, ${ }^{21}$ little is known regarding the mechanisms involved. In this study we performed a series of experiments to determine how PAF affects DNA repair by examining important checkpoints that regulate DNA repair and cell cycle progression. We primarily used mast cells because of the critical role these cells have in UV-induced immune suppression and skin cancer induction, ${ }^{15,28}$ and also because the dermis where they reside is targeted by UV-induced PAF. ${ }^{18}$

\section{Results}

cPAF impairs proliferation in mast cells. Conflicting studies show that PAF activates or inhibits cell proliferation, suggesting potential roles in tumor promotion or tumor suppression. ${ }^{29}$ To understand the definitive role of PAF on transformed human mast cells (HMC-1), we cultured HMC-1 cells with $5 \mu \mathrm{g} / \mathrm{ml}$ of carbamyl PAF (cPAF), a

\footnotetext{
'Department of Immunology, The University of Texas MD Anderson Cancer Center, Houston, TX, USA; ${ }^{2}$ Dipartimento Scienze della Vita e dell'Ambiente, Universita Politecnica delle Marche, Ancona, Italy and ${ }^{3}$ The University of Texas, Graduate School for Biomedical Sciences, Houston, TX, USA

*Corresponding author: SE Ullrich, Department of Immunology University of Texas, MD Anderson Cancer Center, 1515 Holcombe Boulevard, Unit 902, Houston, TX 77030, USA; Tel: +1 713563 3264; Fax: +1 713563 3280; E-mail: sullrich@mdanderson.org

Abbreviations: ATM, Ataxia telangiectasia mutated; ATR, Ataxia telangiectasia and rad related; CPAF, carbamyl platelet-activating factor; CDK, Cyclin-dependent kinase; CXCR4, Chemokine C-X-C motif receptor 4; ERK, Extracellular signal-regulated kinase; FACS, Fluorescence activated cell sorting; GADD45, Growth arrest and DNA damage-inducible 45; HMC-1, Human mast cell line 1; PAF, Platelet-activating factor; PCNA, Proliferating cell nuclear antigen; UV, Ultraviolet

Received 19.12.14; revised 16.3.15; accepted 17.3.15; Edited by H-U Simon
} 
non-hydrolysable bioactive PAF agonist, and observed a significant decline in cell proliferation (Figure 1a). Similarly, the rate of incorporation of the thymidine analog ethynyl deoxyuridine (EdU) into DNA declined after cPAF exposure, in a dose- and time-dependent manner (Figure 1b). PAF treatment also had a similar effect in nontransformed cells. Normal mast cells were isolated from a buffy coat and treated with cPAF as described above. Although these cells had a lower basal rate of cellular growth, cPAF treatment also induced a dose-dependent decrease in proliferation (Figure 1c). These results indicate that the cellular response to CPAF is not affected by transformation.

cPAF induces cell cycle arrest at G2-M. To identify the compartments of the cell cycle affected by cPAF, we stained $\mathrm{EdU}^{+}$cells with propidium iodide and calculated the percentage of proliferating cells. We detected a dosedependent reduction in DNA synthesis (S phase), and arrest at G2-M, 24 and $48 \mathrm{~h}$ after cPAF treatment (Figure 2). A less pronounced but similar effect was observed at the G0-G1 phase 24 and $48 \mathrm{~h}$ after cPAF treatment. This indicates that cPAF causes a long lasting effect at $\mathrm{G} 2-\mathrm{M}$, reminiscent of chemotherapeutic drugs affecting G2-M transition. ${ }^{30,31}$

Because cPAF largely arrests cells at G2-M, we sought to determine the targets altered during this process. We used fluorescently-labeled cell sorting to separate EdU' from EdU HMC- 1 cells $24 \mathrm{~h}$ after cPAF exposure. Protein lysates were analyzed using reverse phase protein arrays (RPPA). ${ }^{32}$ The RPPA results (Supplementary Figure 1) indicated that CPAF reduces the expression of CDK1 (cyclin-dependent kinase) and cyclin-B1, critical for G2-M transition, and of cyclins D1 and E1, E2F1, and CDK2, essential at G0-G1. These results agree with the fluorescence-activated cell sorting (FACS) analysis indicating that cPAF arrests cells mainly at G2-M and G0-G1 (Figure 2). These observations were confirmed by immunoblotting, in which a dose-dependent decline was observed in cyclin-B1 and CDK1 expression. We also observed a slight decrease in cyclin-D1 and CDK2/4, which are essential at G0-G1. In addition, the highest dose of cPAF induced a consistent decrease in c-Myc (Figure 3a), likely affecting the expression of its downstream target, cyclin-D1. ${ }^{33}$ Similar changes were observed for cyclin-B1 after exposing primary mast cells to cPAF (Figure $3 b$ ), thus confirming that the effects of cPAF were not restricted nor affected by transformation. Next, we conducted experiments to confirm that the effect of CPAF was similar to that of naturally occurring PAF. Natural PAF has a shorter life and is more susceptible to enzymatic degradation as compared with $\mathrm{CPAF}^{34}$ this makes cPAF a reliable choice to study PAF effector functions. As expected, natural PAF showed a strong activation of p21 3-h post exposure, and a decrease of cyclin-B1 6-h after exposure (Figures $3 c$ and $d$ ). These results indicate that the effector function of cPAF closely resembles that of natural PAF, although the latter is more susceptible to degradation and thus its effects occurred within shorter incubation times.

cPAF effect on the G2-M mitotic complex. The G2-M DNA damage checkpoint prevents eukaryotic cells from entering mitosis allowing for proper repair of damaged DNA, thereby preventing genomic instability. ${ }^{35}$ The G2-M mitotic transition is regulated by cyclin-dependent kinase 1 (CDK1) that associates with the regulator cyclin-B1. The phosphorylation of Cdc2 at Tyr15 measures the activation status of Cdc2 during progression into mitosis. ${ }^{36}$ Since a significant decrease in cyclin-B1 and CDK1 was observed $24 \mathrm{~h}$ post-cPAF treatment (Figure 3 ), we wanted to understand how the expression of these proteins was modulated during the first $24 \mathrm{~h}$ of cPAF exposure. We found a steady decline in cyclin-B1, total CDK1 and p-Cdc2 (Tyr15) expression starting at 10-h post-cPAF treatment (Figure 4a). The levels of cyclin-B1 and p-Cdc2 (Tyr15) reached their lowest at 22-24-h post-cPAF treatment, as opposed to the control samples (Figure 4b). The cPAF-induced reduction in these proteins was similar in HMC-1 cells synchronized at G0 by serum starvation (Supplementary Figure 2). Because serum deprivation affected the viability of $\mathrm{HMC}-1$ cells, but not the cPAF-induced modulation of cyclin-B1, CDK1, and p-Cdc2 (Tyr15) expression, we decided to avoid it in our subsequent experiments. To quantify differences in protein expression, we obtained normalized blot densities for cyclin-B1, CDK1, and p-Cdc2 (Tyr15; Figure 4d). Our results show that after adding cPAF, cyclin-B1 expression peaked at $6 \mathrm{~h}$ and gradually decreased over the remaining time, and total CDK1 peaked at $2 \mathrm{~h}$ and followed a nearly flat trajectory during the 24-h cPAF exposure. CDK1 expression did not surpass the peak of p-Cdc2 (Tyr15), an indication of CDK1 inactivity, at earlier time points. However, the expression of CDK1 remained higher than p-Cdc2 (Tyr15) 14-h post-cPAF exposure. These results indicate that while the phosphorylation of Cdc2 decreases, an indication of active CDK1, the level of cyclin-B1 does not recover to resume cell cycle progression. This appears to be sufficient to keep cells arrested at G2. To assess whether an inhibitor of the CDK1/ cyclin-B1 complex resulted from cPAF exposure, we analyzed the expression of growth arrest and DNA damageinducible 45 (GADD45) during the same 24-h period. Our results indicate an increased expression of GADD45 at 22$24 \mathrm{~h}$, which coincides with the decreased expression of CDK1/cyclin-B1, suggesting that GADD45 might be affecting this complex (Figure 4c). Finally, to determine whether cPAF activates the MAPK pathway in HMC-1 cells, as has been shown with other innate immune cells, ${ }^{37}$ we measured the activation of extracellular signal-regulated kinase (ERK). Our results indicate a decrease in activated ERK starting 8-h post-cPAF exposure (Supplementary Figure 3), suggesting that cPAF might also affect cell cycle entry through this mechanism. ${ }^{38}$

cPAF exposure increases p21 expression. Because p21 regulates cell proliferation through its involvement with proliferating cell nuclear antigen (PCNA), we determined whether cPAF affected this interaction. cPAF induced a measurable reduction in PCNA expression (Figure 5a). Conversely, the expression of p21 showed a dosedependent increase. These findings indicate that cPAF may reduce cell proliferation by unbalancing the interaction between PCNA and p21 to the extent that abundance of p21 may result in higher occupation of PCNA sites, thereby preventing PCNA-driven cell proliferation. ${ }^{39}$ To determine whether this was the case, we performed 
a

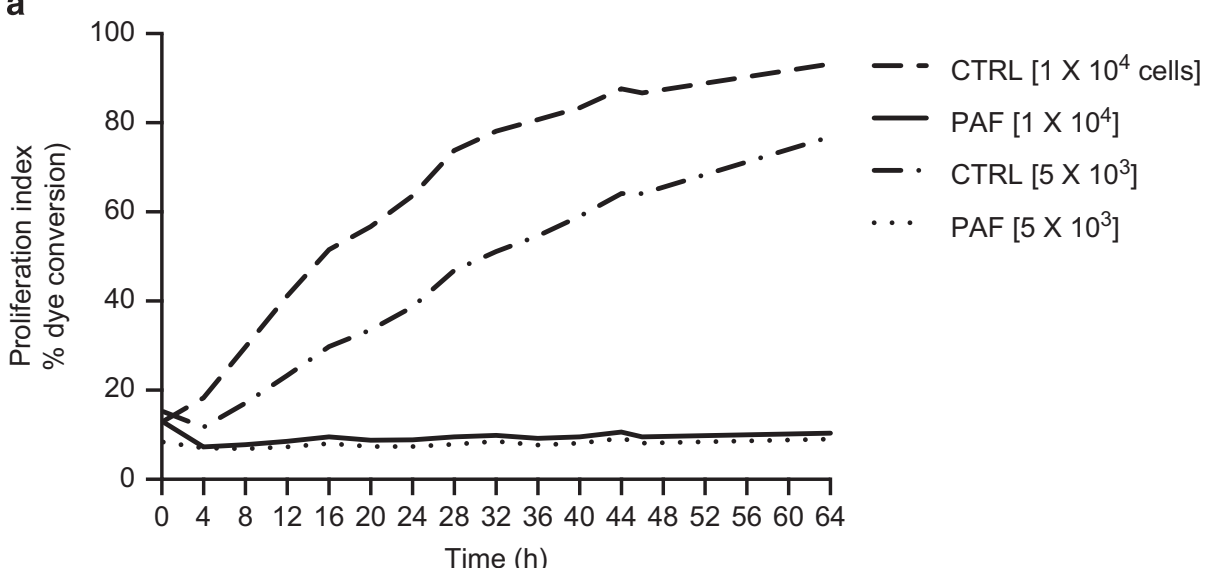

b Control
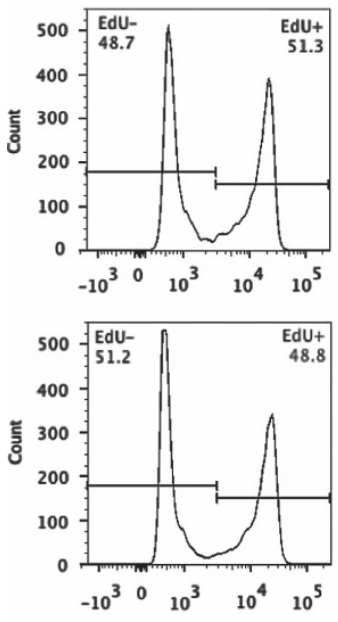

EdU
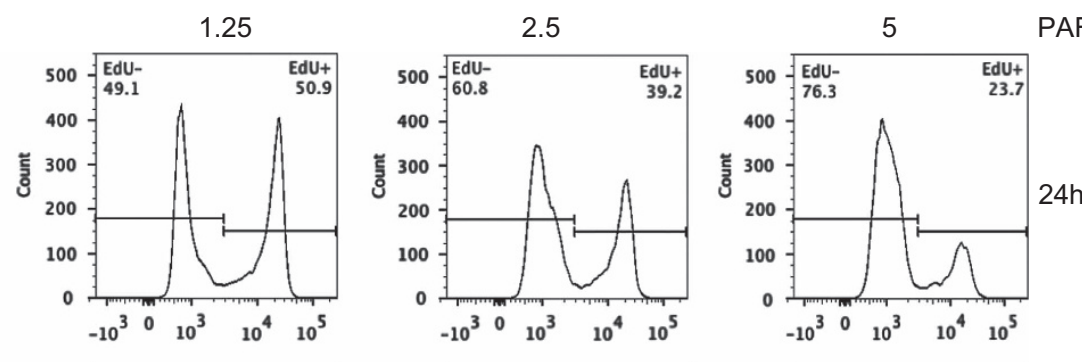

$\operatorname{PAF}(\mu \mathrm{g} / \mathrm{mL})$
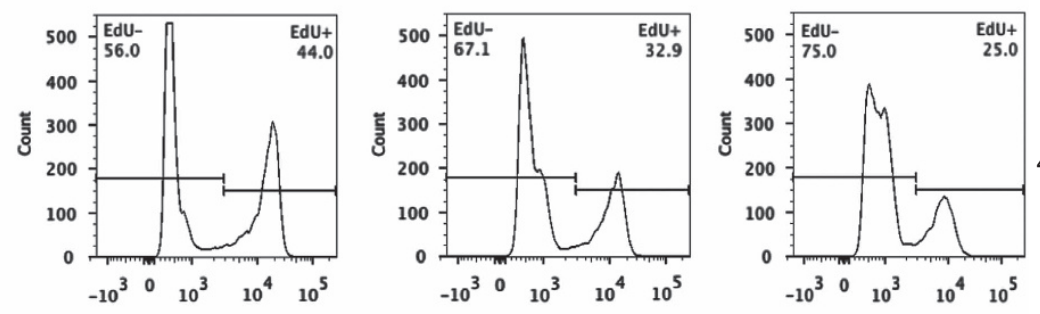

C
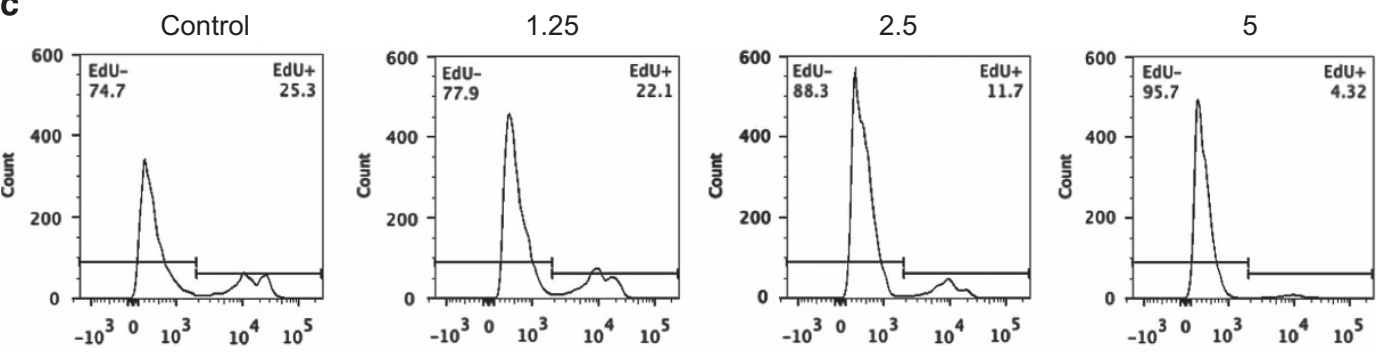

$\operatorname{PAF}(\mu \mathrm{g} / \mathrm{mL})$
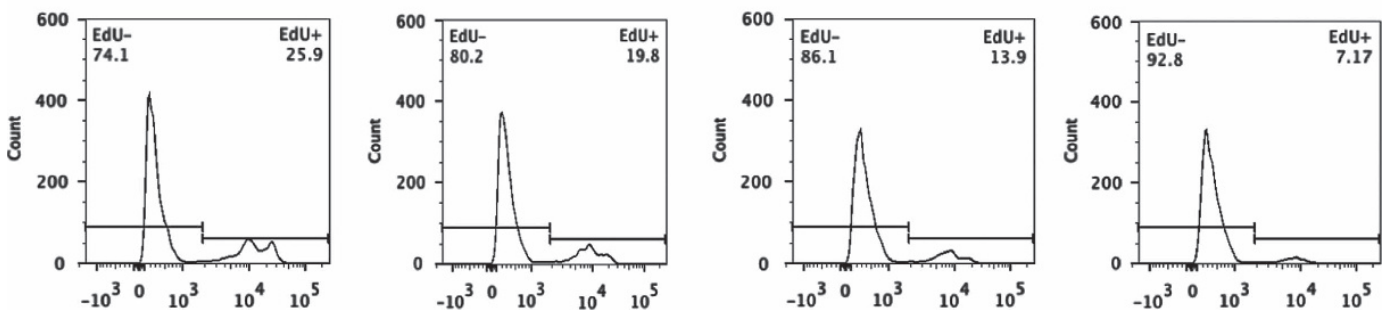

$24 \mathrm{~h}$

$48 \mathrm{~h}$

EdU

Figure 1 PAF suppresses cell proliferation. (a) HMC-1 cells, at the indicated densities per well, were treated with CPAF and proliferation measured by dye conversion. (b) Cells were treated with different concentrations of CPAF $(0-5 \mu \mathrm{g} / \mathrm{ml})$ and proliferation was measured by EdU incorporation. Cells were harvested 24- and 48-h post-cPAF treatment. (c) Effect of CPAF on the proliferation of normal mast cells was measured by EdU incorporation 

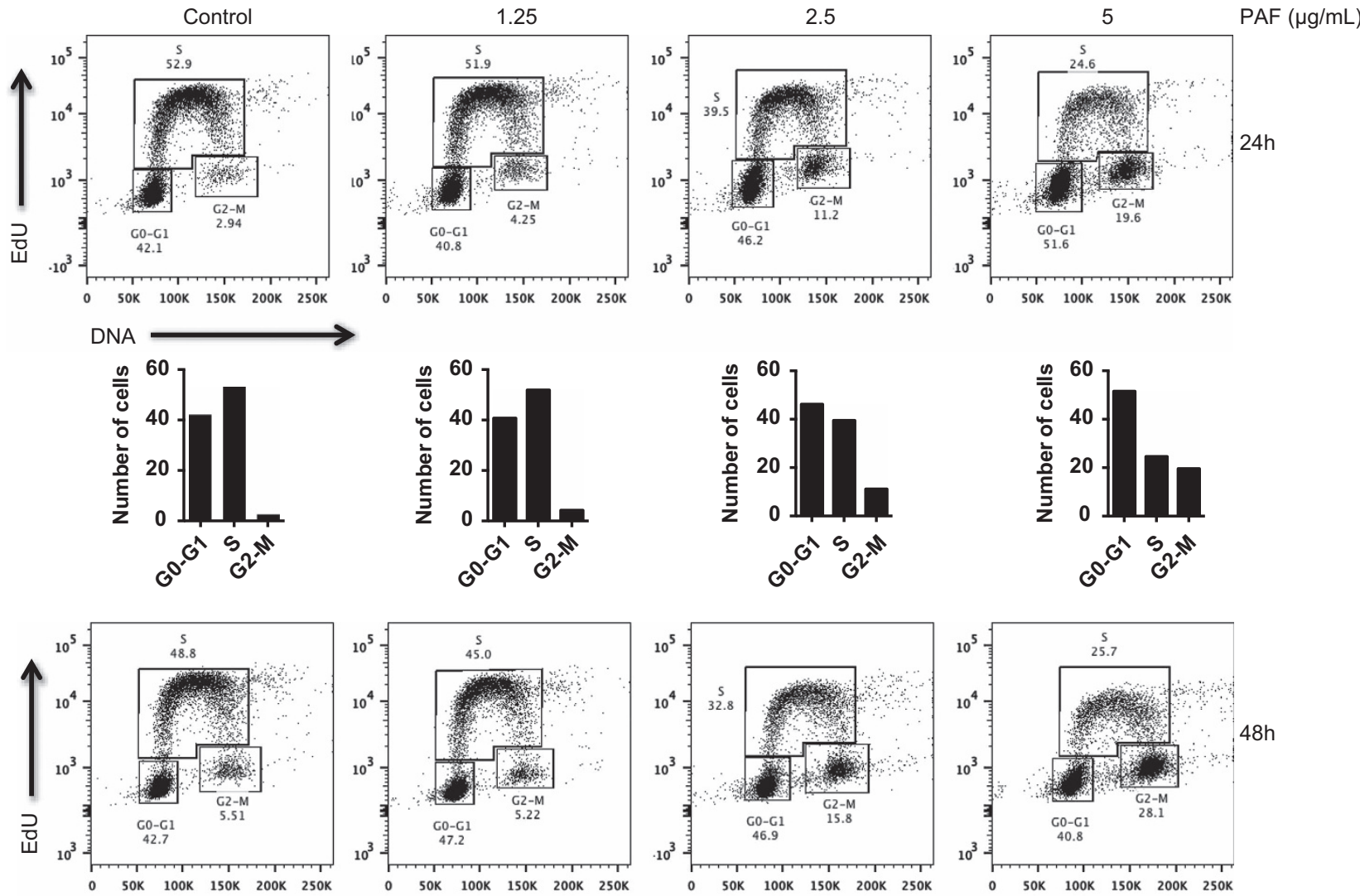

DNA
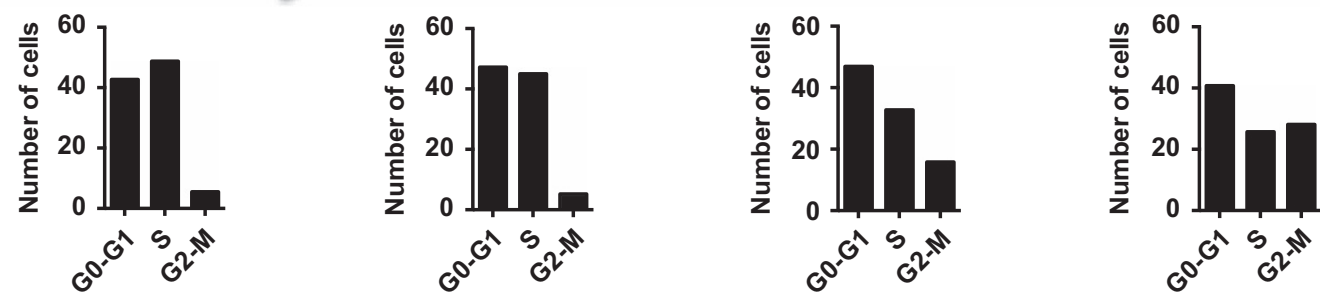

Figure 2 cPAF disrupts cell cycle progression. HMC-1 cells were treated with different doses of cPAF, and incubated for 24 and $48 \mathrm{~h}$. Cells positive for propidium iodide but negative for EdU were increased at G2-M and G0-G1. The number of double positive cells $\left(\mathrm{PI}^{+}\right.$and EdU $)$, indicative of DNA synthesis, was decreased in cells treated with cPAF

immunoprecipitation assays, capturing with PCNA antibody and blotting with anti-p21 (Figure 5b). As indicated by immunoblotting and densitometry analysis, we found that cPAF induced a dose-dependent increase in p21 bound to PCNA (Figure 5b). Similarly, when anti-p21 was used as the capture antibody and anti-PCNA antibody for immunoblotting, we observed higher PCNA levels in control samples as opposed to cPAF-treated samples (Figure $5 \mathrm{~b}$ ). These findings indicate that CPAF-induced p21 expression likely leads to the occupation of PCNA sites, impairing cell proliferation.

Next, we determined if cPAF-induced expression of p21 was associated with $\mathrm{p} 53$ activation. Although we observed a discrete increase in p53 expression with robust expression of p21 in PAF-treated mast cells (Figure 5c), we wanted to determine whether PAF-induced p21 expression was associated with p53 upregulation in different cell types. We exposed HCT-16 cells, carrying wild-type p53, and p53deficient Saos-2 cells to different doses of cPAF. Our results indicate that while cPAF failed to induce p21 expression in
Saos-2 cells, it induced a robust expression of p53 and p21 in HCT-16 cells. These results indicate that cPAF-induced expression of p21 is p53 dependent (Figure $5 d$ ). Next, to identify the effect of cPAF on the phosphorylation of p53, we use a panel of antibodies against the following phosphorylation sites: S15, S9, S37, S6, S46, S20, S392, and T81. We observed that CPAF increased the expression of phosphorylated p53 at S392 (Figure 5e), probably enhancing its binding capacity to the promoter region of p21 as described by Kapoor and Lozano. ${ }^{40}$ Taken together, these findings unravel a novel and yet undiscovered role of CPAF on key proteins critical for cell proliferation that indicate a potential role in tumor suppressor mechanisms.

cPAF drives transformed mast cells into apoptosis. Because cPAF treatment impairs mast cell proliferation, it was important to investigate the fate of these cells. Using FACS and TUNEL (terminal deoxynucleotidyltransferasemediated dUTP-biotin nick end labeling) analyses, we 

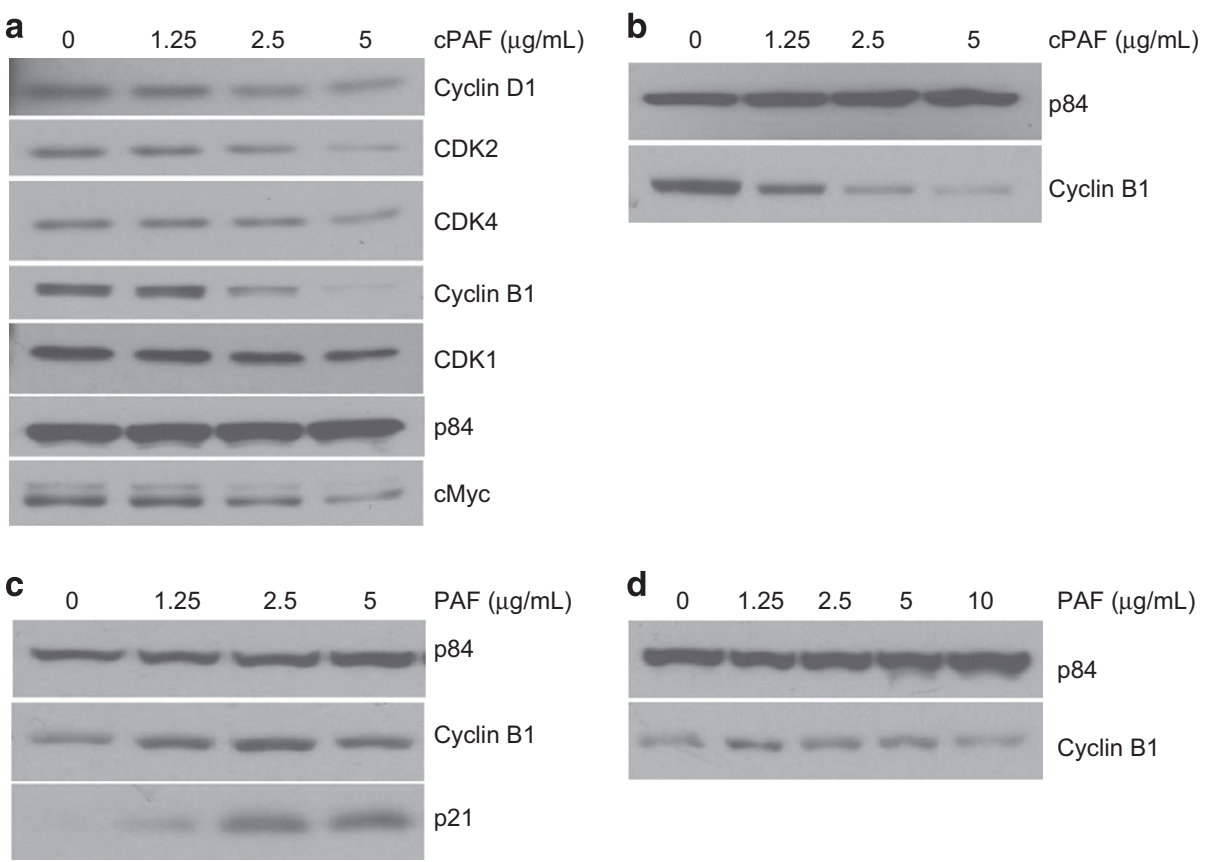

Figure 3 cPAF decreases protein levels of key components of the cells cycle. (a) Protein extracts from cells exposed to different concentrations of cPAF for $24 \mathrm{~h}$ were analyzed by immunoblotting. A noticeable decrease as a function of concentration response is observed in cyclin-B1, CDK2/4 and c-Myc. (b) cPAF also induced a decrease in cyclin-B1 expression in normal, nontransformed mast cells, similar to that observed in transformed mast cells. (c) Similar to cPAF, natural occurring PAF also induced an increased expression of p21 within $3 \mathrm{~h}$ after exposure; however, the effect on cyclin-B1 was more evident at 6-h post exposure and higher concentration of natural PAF. (d) p84 expression was used as the loading control

observed that cPAF-exposed HMC-1 cells undergo apoptosis in a concentration-dependent manner (Figure 6a). We also measured the expression of cleaved PARP-1 and cleaved caspase 3 by immunoblotting following cPAF exposure and observed a steady induction of cleaved PARP-1 starting at $6 \mathrm{~h}$ and a gradual increase in cleaved caspase 3 starting at $10 \mathrm{~h}$ (Figure 6b). We also determined the accumulation of fragmented DNA from apoptotic cells by measuring the expression of $\gamma-\mathrm{H} 2 \mathrm{AX}$ during the same time period. Our results show that, in line with the expression of cleaved PARP-1 and caspase 3, the dying cells also accumulate increasing amounts of phosphorylated H2AX (Figure 6b). This indicates that $\mathrm{CPAF}$-induced impaired cell proliferation is followed by apoptosis.

cPAF impairs the DNA damage response. The process of DNA repair is inherently linked to cell cycle progression and its checkpoints. To determine whether cPAF also affected components of the DNA damage repair mechanism, we measured the protein expression of several factors critical in this process, including ATR, ATR-interacting protein and microcephalin/BRIT-1. Our results show that cPAF decreases BRIT-1 levels, critical for the repair of ionizing radiation and UV-related DNA damage, in a concentration-dependent manner (Figure 7a). Similarly, cPAF induced a moderate decrease in ATR and ATR-interacting protein in HMC-1 cells. This indicates that cPAF might impair a proper DNA damage response if cells are exposed to damaging agents. To test this, we asked whether cPAF affected the localization of p-ATR and p-ATM to sites of DNA damage. Briefly, we placed keratinocyte monolayers (HaCat) onto multi-chamber slides; the cells were pre-incubated with $\mathrm{CPAF}$ for 24 and $48 \mathrm{~h}$ followed by UV or ionizing radiation (IR). Immunofluorescence staining demonstrated that cells exposed to cPAF followed by UV exposure, had a lower number of $p$-ATR (S428)-positive foci, as compared with the controls (Figures $7 \mathrm{~b}$ and $\mathrm{c}$ ). Similarly, cells that were exposed to IR had a lower number of localized p-ATM (S1981)-positive foci when compared with the controls (Figures $7 \mathrm{~b}$ and $\mathrm{c}$ ). These observations indicate that cPAF disrupts both the cell cycle and the DNA repair mechanism, potentially increasing the risk of genomic instability.

The recruitment of the phosphorylated form of histone $\mathrm{H} 2 \mathrm{AX}(\gamma-\mathrm{H} 2 \mathrm{AX})$ is another indication of a rapid DNA damage response mechanism after cells are exposed to genomic insults. Hence, the expression of $\gamma-\mathrm{H} 2 \mathrm{AX}$ in $\mathrm{CPAF}-$ and UVexposed HMC-1 cells was analyzed. Our results show that cPAF treatment delays the expression of $\gamma-\mathrm{H} 2 \mathrm{AX}$ in UV-treated mast cells, compared with cells exposed only to UV radiation (Figure 7d). This suggests that the presence of cPAF hampers the repair of DNA damage induced by UV exposure.

\section{Discussion}

Exposure to moderate UV doses results in the release of PAF by irradiated keratinocytes. ${ }^{13,41}$ Previous studies have shown that PAF has an important role in UV-induced immune suppression $^{3-5,42}$ and skin carcinogenesis, in part by suppressing DNA repair. $^{21}$ Here we demonstrate that PAF profoundly affects key components that regulate the cell cycle and DNA damage response in mast cells and keratinocytes. Contradicting previous reports indicating that PAF promotes 
a

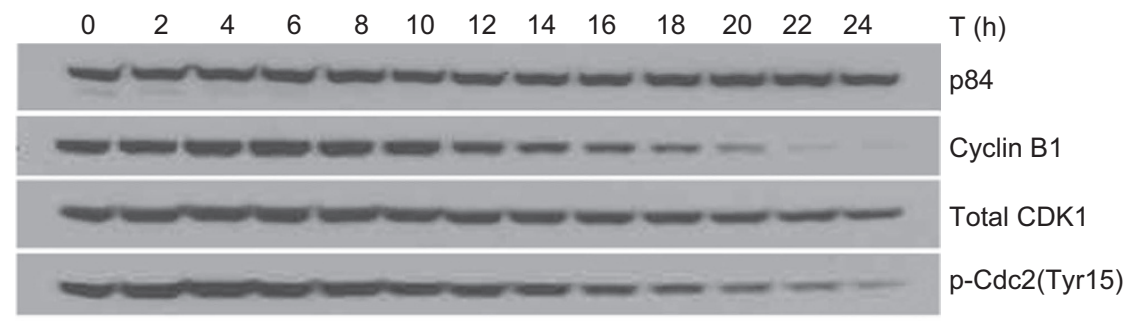

b

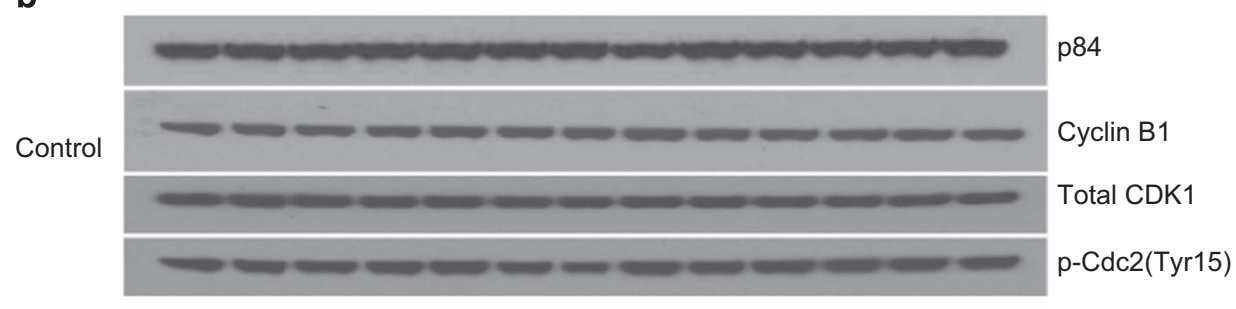

C

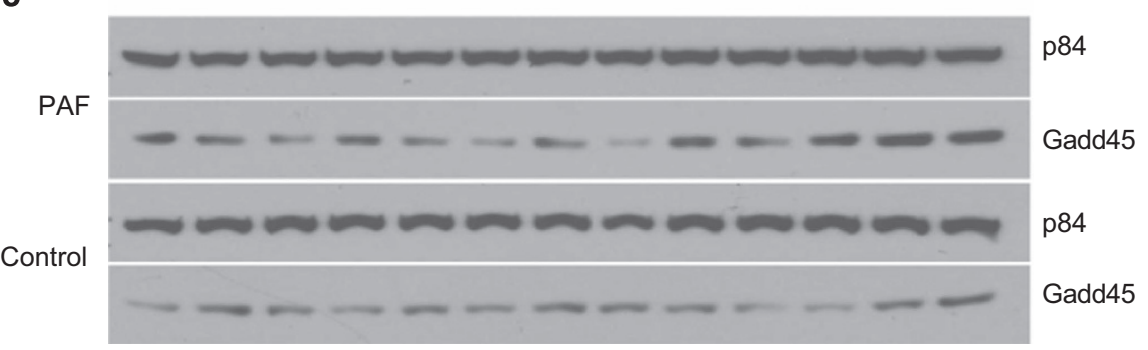

d
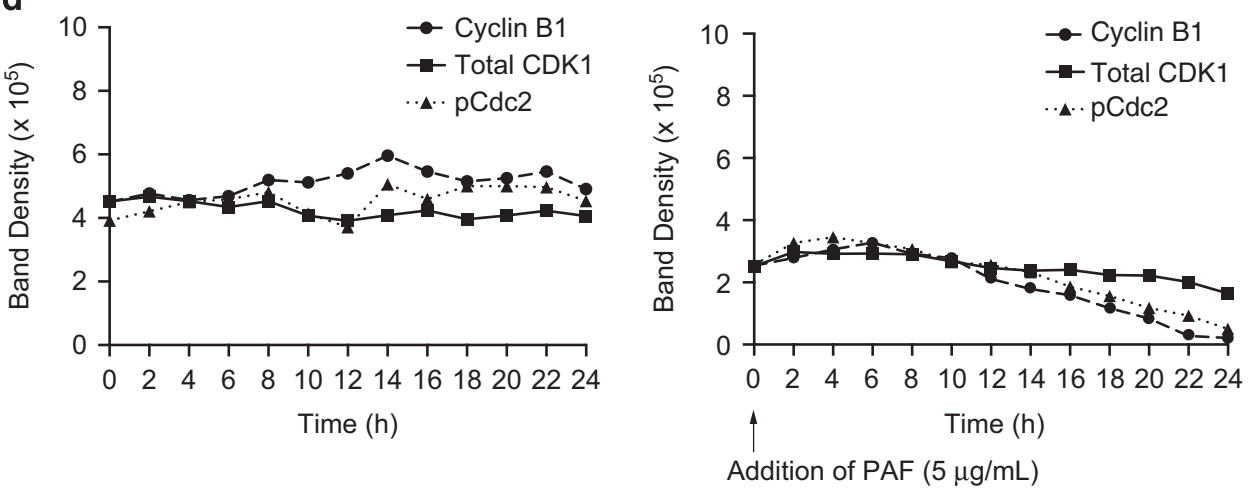

Figure 4 CPAF disrupts the cyclin-B1/CDK1 mitotic complex. (a) Cells were collected every 2-h post-cPAF treatment and expression of cyclin-B1, total CDK1 and phosphorCdc2(tyr15) determined by immunoblotting. (b) Nontreated control samples harvested at the same time points. (c) Expression of GADD45 in cPAF-treated and control cells. p84 expression was used as the loading control. (d) Blot density for cyclin-B1, total CDK, and phospho Cdc2(Tyr15), was determined using ImageJ on blots from control and cPAF-treated cells

proliferation in keratinocytes ${ }^{43}$ and metastasis in a variety of tumor cells, ${ }^{29}$ we demonstrate that in HMC-1 cPAF, a nonhydrolysable PAF analog, suppresses rather than accelerates cell growth (Figure 1a), suggesting a potential function in tumor suppression. cPAF also affected normal mast cells demonstrating that its effect was not exclusive to transformed cells (Figures $1 \mathrm{~b}$ and $\mathrm{c}$ ).

FACS analysis showed that CPAF exposure induces a potent reduction in DNA synthesis, and a significant arrest at G2-M. However, cPAF only had a discrete effect at G0-G1 (Figure 2). Our initial findings obtained by RPPA identified key regulators of the cell cycle affected by cPAF (Supplementary
Figure 1). RPPA analysis showed that CPAF downregulated proteins actively involved in the cell cycle including cyclin-B1, CDK1, cyclins D1/E, and CDK2. We next observed that cPAF promotes a continuous degradation of cyclin-B1 in a concentration-dependent manner to almost null levels 24and 48-h post exposure (Figure 3). These results and our previous observations indicated that the cPAF-induced cytostatic effect in HMC-1 cells is predominantly at G2-M through the disruption of the CDK1/cyclin-B1 mitosis-promoting complex, ${ }^{44-47}$ suggesting that $\mathrm{CPAF}$-induced reduction of cyclin-B1 expression forces cells to exit from mitosis. ${ }^{46}$ The effect of cPAF on cyclin-B1 in transformed cells underscores 
a
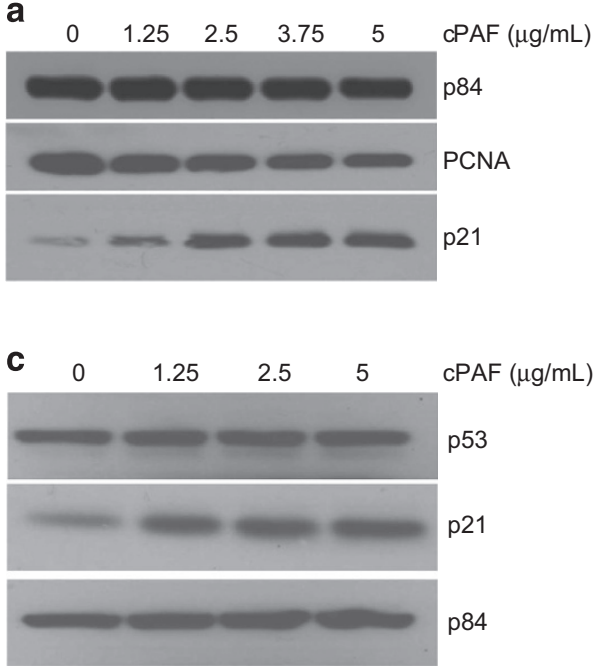

d
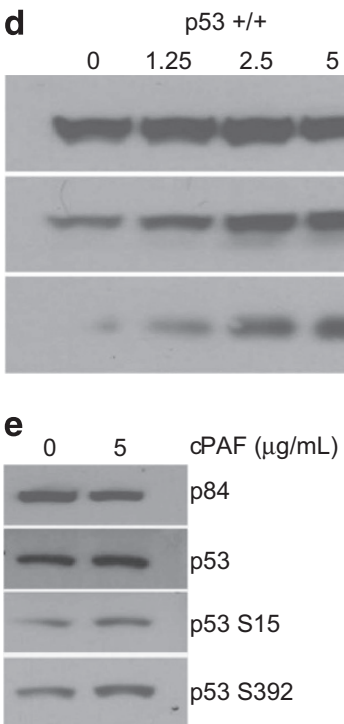

b
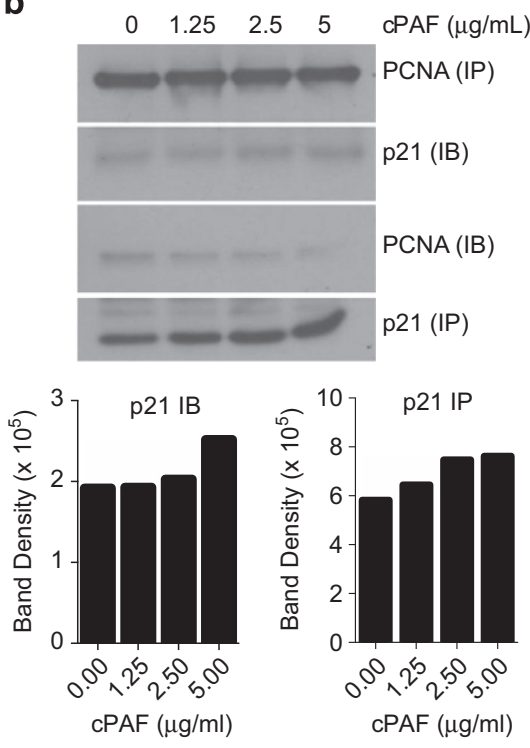

p53 -/-

$1.25 \quad 2.5 \quad 5$

$\mathrm{cPAF}(\mu \mathrm{g} / \mathrm{mL})$

p84

p53

p21

Figure 5 cPAF increases the expression of p21 in a p53-dependent manner, and affects its interaction with PCNA. (a) Expression of PCNA and p21 in cells treated with different doses of CPAF and harvested 24-h post treatment. (b) Lysates from CPAF-treated cells were immunoprecipitated with anti-PCNA (PCNA IP) and immunoblotted wi th antip21 (p21 IB), or immunoprecipitated with p21 (p21 IP) and blotted with anti-PCNA (PCNA IB). Histograms represent normalized band density as determined by Image J analysis of the Western blots. (c) CPAF induced an increased expression of p21 with no visible changes in p53 expression in mast cells; however, the effect of cPAF is more evident in HCT-16 cells carrying wild-type p53, which show a robust expression of both p21 and p53 (d, left panel); Saos-2 cells were used as p53-null control (d, right panel). (e) cPAF also induced the expression of phosphorylated p53 at S392, and a subtle increased in p53 S15, as compared with the control. p84 expression is used as the loading control

potential therapeutic applications of this phospholipid, since cyclin-B1 is a regulator of the CDK1/cyclin-B1 complex, and is critical for mitotic progression. ${ }^{45,46}$ In addition, cPAF also induced a consistent decrease in c-Myc expression throughout all our experiments, providing further evidence it is a potent suppressor of cellular proliferation.

In our experiments the effects of cPAF resemble those of naturally occurring PAF, with few minor differences. Whereas most of cPAF-induced changes occurred at the end of $24 \mathrm{~h}$ of exposure, natural PAF induced changes in p21 and cyclin-B1 expression within the first $6 \mathrm{~h}$ of exposure. This difference can be explained by the incorporation of the carbamyl radical to PAF, which makes it more resistant to metabolic degradation without compromising its biological activities. ${ }^{34}$
To understand how cPAF affected key components regulating the G2-M mitotic complex, we studied the fluctuation of cyclin-B1, CDK1, and p-Cdc2 (Tyr15) during a 24-h time frame. Our results clearly indicate that cPAF depresses expression of cyclin-B1, coinciding with the reduced phosphorylation of Cdc2 at Tyr15 and reduced expression of total CDK1 starting $10 \mathrm{~h}$ following cPAF addition. As observed by the peak in the expression of cyclin-B1, and compared with the controls, cPAF seems to accelerate the cells into mitosis; indeed, cyclin-B1 reaches its maximum after $6 \mathrm{~h}$ but never recovers to resume cell cycle. The effect of cPAF on cyclin-B1 is unique because the decrease in p-Cdc2 (Tyr15) at 22-24-h post-cPAF exposure shows that CDK1 is readily active to resume cell cycle progression, however, the decreased 
a
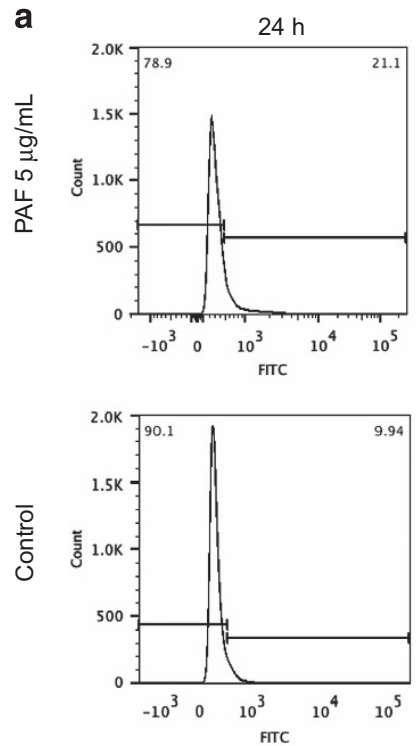
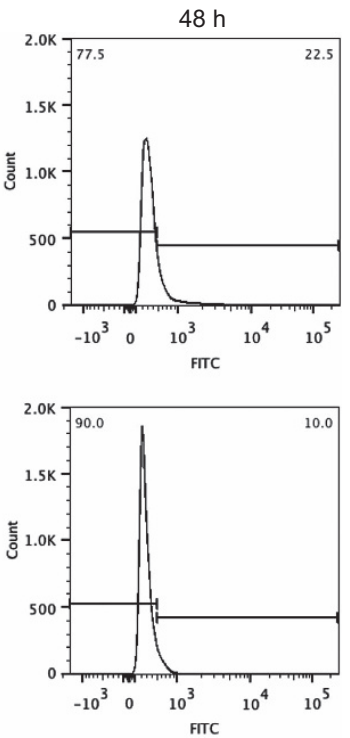

b

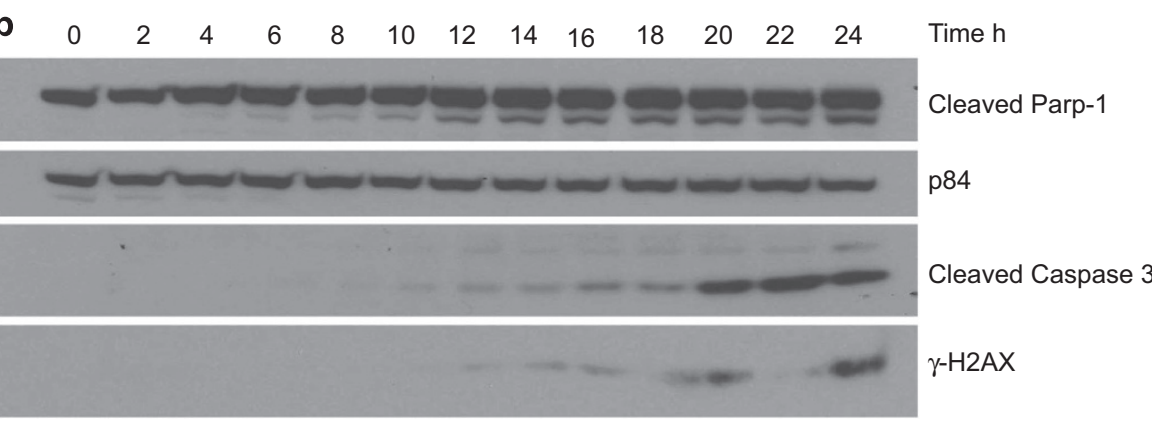

Figure 6 CPAF induces expression of pro-apoptotic markers. (a) HMC-1 cells were treated with $5 \mu \mathrm{g} / \mathrm{ml}$ of cPAF and the number of apoptotic cells was measured $24-$ and 48 -h post-cPAF treatment. (b) HMC-1 cells were treated with $5 \mu \mathrm{g} / \mathrm{ml}$ of CPAF and samples were harvested at the indicated time points. Expression of cleaved Parp-1, cleaved Caspase and $\gamma$-H2AX was determined by Western analysis. p84 expression is used as the loading control

expression in cyclin-B1 likely impairs this process and blocks the cells from entering mitosis. Another mechanism that prevents cell cycle entry is the reduction in ERK activity, $^{38}$ and in this study we found that cPAF exposure reduces the expression of activated ERK (Supplementary Figure 3). This finding is in contradiction to previous observations in colorectal cell lines showing PAF-induced increased activation of ERK and p38MAPK. This difference is probably due to the diverse effects of PAF in different cellular contexts. ${ }^{48}$

Our studies provide further evidence that the CDK1/cyclinB1 complex could also be affected by the dual induction of $\mathrm{p} 21$ and GADD45 after cPAF exposure. First, PAF-induced p53dependent induction of p21 leads to the disruption of PCNAcontrolled cell proliferation, contributing to arrest at G0-G1. Second, cPAF-induced increased expression of GADD45, which is described as an inhibitor of the G2-M complex, ${ }^{49-51}$ and is involved in its checkpoint after UV damage, ${ }^{52}$ could be having a major role in the cell cycle arrest at G2. ${ }^{53}$ The evidence we show here indicates that cPAF might be affecting other compartments of the cell cycle, however our results show that by disrupting cyclin-B1, G2-M is central to cPAF activity in HMC-1 cells. On the other hand, the decreased cell proliferation and the effect at $\mathrm{G} 2-\mathrm{M}$ also coincide with the cPAF-induced reduction in c-Myc, cyclin-D1, and the cyclin-dependent kinases CDK4 and CDK2 (Figure 3a).
As a consequence of the cPAF-induced arrest at G2-M, the HMC-1 cells show a robust expression of cleaved PARP-1 combined with an increase in cleaved caspase 3 and $\gamma-\mathrm{H} 2 \mathrm{AX}$ (Figure 6). This indicates that PAF-treated cells stall at G2-M, undergo mitotic catastrophe, ${ }^{54}$ and accumulate damaged DNA originated from apoptotic fragmentation ${ }^{55}$ or stalled DNA replication. ${ }^{56}$ Thus, cPAF-induced cell cycle arrest at G2-M is followed by apoptosis in HMC-1 cells.

An effective DNA damage response mechanism is critical to maintain genomic stability. Our previous studies suggest that cPAF might be affecting the capacity of UV-exposed cells to efficiently repair damaged DNA. ${ }^{21}$ Here we show that cPAF exposure induces a significant reduction in critical DNA repair components including ATR, ATR-interacting protein, and Brit1. Using this as reference we tested whether cPAF affected the capacity of cells to mount an early DNA damage response. HMC-1 cells incubated with cPAF and exposed to either UV or ionizing radiation, showed an important decrease in the recruitment of DNA damage response proteins $p$-ATR $(\mathrm{S} 428)^{57,58}$ and $\mathrm{p}-\mathrm{ATM}(\mathrm{S} 1981){ }^{59}$ respectively. Therefore, although extended exposure to cPAF leads to mitotic catastrophe and apoptosis, early events indicate that cPAF disrupts a proper DNA damage response upon genomic insult. This suggests that while PAF is released during chronic inflammatory conditions, or during direct exposure to UV- 

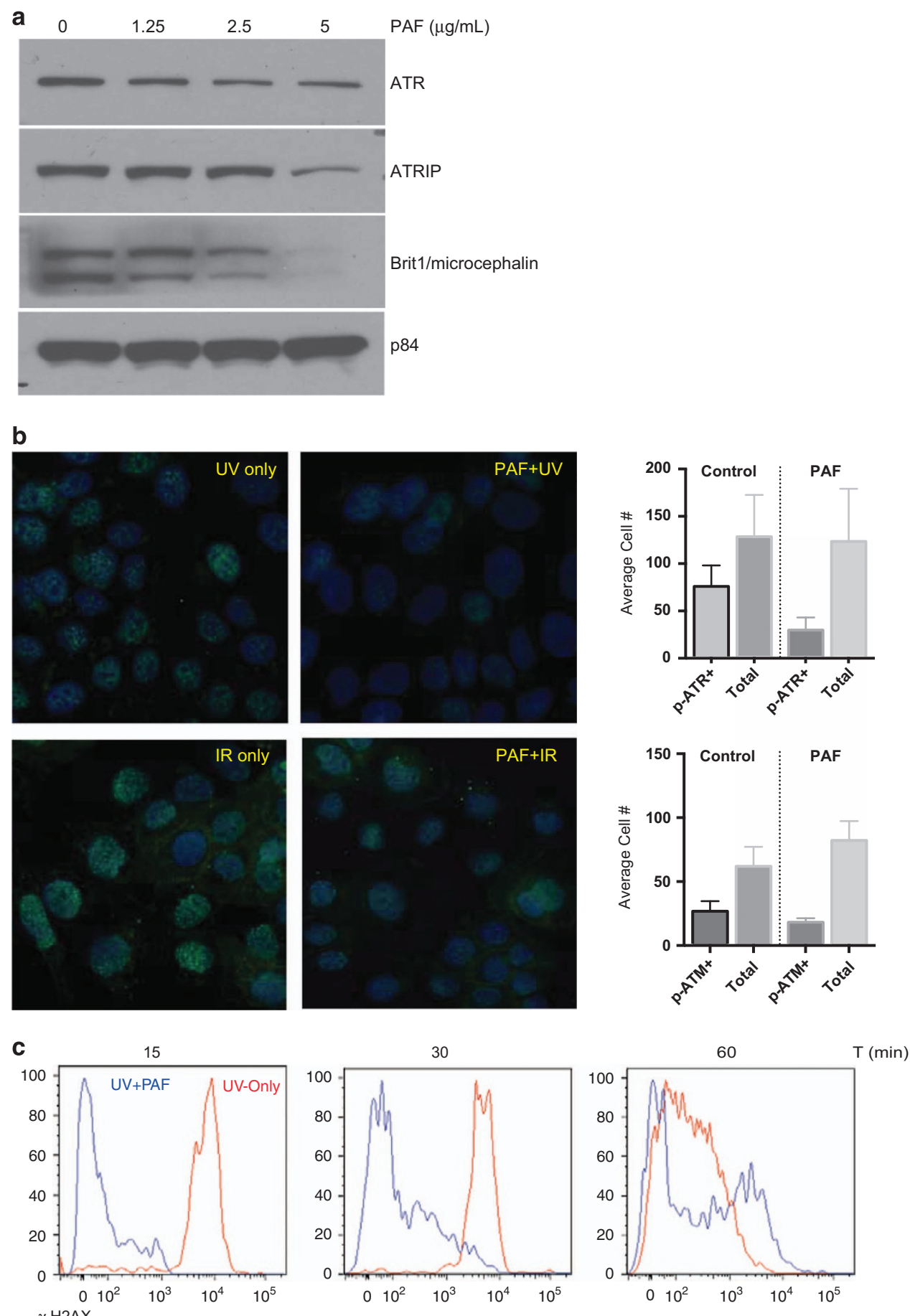

Figure 7 CPAF disrupts the expression of key components of the DNA repair mechanism. (a) HMC-1 cells were treated with different doses of cPAF and harvested 24-h post treatment. Expression of ATR, ATR-interacting protein, and Brit1 was determined by Western analysis. (b) HaCat cells were exposed to UV or IR, or pre-treated with $5 \mu \mathrm{g} / \mathrm{ml}$ of CPAF, and then exposed to UV or IR. Immunofluorescence using antibodies against phosphorylated forms of ATR (S428) and ATM (S1981) was used to visualize the number of cells with positive foci. (c) Histograms represent the average number of $p$-ATR+ and p-ATM+ cells in the CPAF-treated or control cultures. (d) HMC-1 cells were exposed to UV radiation (red) or pre-treated with $5 \mu \mathrm{g} / \mathrm{ml}$ of CPAF and then exposed to $200 \mathrm{~J} / \mathrm{m}^{2} \mathrm{UV}$ radiation (blue). The expression of $\gamma$-H2AX 15, 30, and 60 min after UV exposure was measured by flow cytometry

damaging agents (i.e., sunlight) it is likely that neighboring cells are affected in their capacity to reduce the deleterious effects of these agents.

PAF is released by keratinocytes following low to moderate UV exposure, ${ }^{13,14}$ suggesting that keratinocytes release PAF on a regular basis. Most of the studies examining the effect of PAF on immune function and carcinogenesis suggest it has a negative effect, so the evolutionary advantage of daily release of this inflammatory mediator that has such deleterious effects is not readily apparent. The findings presented here may shed 
some light on the role of PAF in normal and inflamed skin. UV radiation is highly mutagenic and after an acute exposure to low to moderate doses of sunlight, PAF, by inducing cell cycle arrest and promoting apoptosis, may help accelerate the removal of DNA damaged cells from the skin, thus promoting genomic stability. On the other hand, after chronic UV exposure, and coupled with UV-induced inactivation of p53, ${ }^{60}$ PAF suppresses effective DNA repair and promotes tumor growth. By depressing DNA repair, PAF may also augment immune suppression, as studies by Kripke et al. ${ }^{61}$ clearly demonstrated that DNA lesions, particularly pyrimidine dimer formation activate immune suppression. We suggest that PAF has dual functions. In normal skin, it can promote apoptosis and maintain normal homeostasis. However, in chronically irradiated inflamed skin, where one finds UV-induced inactivation of normal tumor suppressor pathways (i.e., p53, PTEN), PAF acts as a classic mediator of inflammation, and through its ability to depress DNA repair contributes to skin cancer induction.

\begin{abstract}
Materials and Methods
Cell culture. HMC-1 cells (kindly provided by Dr. JH Butterfield, Mayo Clinic, Rochester, MN, USA) ${ }^{62}$ were cultured using RPMI- 1640 medium enriched with vitamins, non-essential amino acids, and fetal bovine serum (10\%) under standard culture conditions. In some experiments HaCat cells (kindly provided by Professor Norbert Fusenig, German Cancer Research Center, Heidelberg, Germany) ${ }^{63}$ were used. These cells were cultured as described above. Cell lines were validated by STR DNA finger printing by the MD Anderson Cancer Center Characterized Cell Line Core using the AmpF $\ell$ STR Identifier kit according to manufacturer instructions (Applied Biosystems cat 4322288). The STR profiles were compared to known ATCC fingerprints (ATCC.org), to the Cell Line Integrated Molecular Authentication database (CLIMA) version 0.1.200808 (http://bioinformatics.istge.it/clima/) ${ }^{64}$ and to the MD Anderson fingerprint database. The STR profiles matched known DNA fingerprints or were unique.
\end{abstract}

Isolation of normal mast cells. Normal mast cells were isolated from an adult blood buffy coat obtained from an undisclosed healthy donor from the Gulf Coast Regional Blood Center (Human Research Protocol LAB-03-0390- MDACC), by partially depleting T and B cells followed by cell sorting using anti-CD34 antibody. CD34+ cells were cultured in Stempro medium enriched with IL-6, IL-3, human recombinant stem cell factor, interleukin-6, and interleukin-3. After several weeks in culture, all the viable cells stained positive for toluidine blue, tryptase, and were CD117+ (cKit).

Cell proliferation. The rate of proliferation was analyzed using Alamar blue according to the manufacturer's instructions (Life Technologies, Carlsbad, CA, USA), as described previously. ${ }^{65}$ Briefly, we cultured $1 \times 10^{4}$ and $1 \times 10^{3} \mathrm{HMC}-1$ cells in 96-well plates with and without CPAF (Cayman Laboratories, Ann Arbor, Ml, USA) for $24 \mathrm{~h}$. After incubation, we resuspended the cells in fresh medium for another $64 \mathrm{~h}$, and the rate of proliferation was analyzed every $4 \mathrm{~h}$ by Alamar blue. The conversion of the nonfluorescent indicator dye to a bright red color by metabolically active cells was monitored using a microplate reader. In addition, we also used the thymidine analog EdU after cells were treated with CPAF; the cells were incubated for 24 and $48 \mathrm{~h}$ at different concentrations of $\operatorname{CPAF}(1.25,2.5$, and $5 \mu \mathrm{g} / \mathrm{ml})$, followed by $2 \mathrm{~h}$ incubation with EdU $(10 \mu \mathrm{M})$ in cPAF-free medium. EdUpositive cells were identified using Alexa Fluor 488 Click-iT reaction kit (Life Technologies), followed by propidium iodide staining. Cells were plotted according to their DNA content and EdU-Alexa 488 staining to determine the number of cells in different phases of the cell cycle.

Immunoblotting. Protein samples were obtained from treated and nontreated cells using RIPA lysing buffer. Briefly, cell pellets were resuspended in lysing buffer and immediately frozen at $-80^{\circ} \mathrm{C}$. BCA protein assay was used to determine protein concentrations (Pierce BCA Protein Assay kit, Thermo Scientific, Waltham, MA, USA). The antibodies to detect cyclin-B1, cleaved caspase 3, c-Myc, Brit1, ATR, $\gamma$-H2AX, p-cdc2, cyclin-D1, p-ATM (S1981), p-ATR (S428), p-ERK, ERK,
GADD45, and p-p53 (S15, S9, S37, S6, S46, S20, S392, and T81) were used at $1: 1000$ dilution (Cell Signaling Labs, Danvers, MA, USA); antibodies to p21, cyclin $A$ and CDK1 were used at 1:1000 dilution (Becton Dickinson, San Jose, CA, USA); antibodies to p53 (DO-1), CDK2, and CDK4 were used at 1:500 dilution (Santa Cruz Biotechnology, Dallas, TX, USA); the antibody to p84 was used at 1:1000 dilution (Genetex, Kennesaw, GA, USA); the antibody to PCNA was used at 1:1000 dilution (Dako Laboratories, Carpinteria, CA, USA). Natural PAF was purchased from Cayman Laboratories. Densitometry analysis, when necessary, was performed using ImageJ software (http://imagej.nih.gov/ij/).

Analysis of the cell cycle. After each treatment cells were further incubated for $2 \mathrm{~h}$ with $10 \mu \mathrm{M} \mathrm{EdU}$ in cPAF-free medium. The cells were fixed and the incorporated EdU analog was detected following the manufacturer's instructions (Click it, Invitrogen); as a final step, the cells were incubated with P.I. staining solution containing RNAse. The cells were analyzed using LSRII or Fortessa flow cytometers. Data acquisition was carried out using Diva software (BD Biosciences, San Jose, CA, USA) and further analyzed using FlowJo software (Ashland, OR, USA).

TUNEL assay. TUNEL (Promega, Madison, WI, USA) was performed on HMC-1 cells. Briefly, DNA strand breaks were labeled with fluorescein-12-dUTP. The green fluorescence of apoptotic cells was detected by fluorescence activation cell sorting.

Assessment of DNA damage response. HMC-1 cells were pre-cultured for $24 \mathrm{~h}$ with $5 \mu \mathrm{g} / \mathrm{ml}$ of CPAF followed by UVB $\left(200 \mathrm{~J} / \mathrm{m}^{2} ; 290-320 \mathrm{~nm}\right)$ or IR (10 Gy). Cells were allowed to recover for $1 \mathrm{~h}$ and then were fixed with $4 \%$ paraformaldehyde for $10 \mathrm{~min}$. Cells exposed to UV light were stained against p-ATR and those exposed to IR stained against p-ATM, as a measure of DNA damage response.

\section{Conflict of Interest}

The authors declare no conflict of interest.

Acknowledgements. This work was supported by a grant from the National Cancer Institute (CA131207) and the Cancer Prevention and Research Institute of Texas (RP120777). The histology, characterized cell line core, proteomics reverse phase protein array, and flow cytometry facilities at the MDACC are supported in part by a core grant from the $\mathrm{NCl}$ (CA16672). We thank Nasser Kazimi for technical support.

1. Kripke ML. Antigenicity of murine skin tumors induced by ultraviolet light. J Natl Cancer Inst 1974; 53: 1333-1336.

2. Fisher MS, Kripke ML. Suppressor T lymphocytes control the development of primary skin cancers in ultraviolet-irradiated mice. Science 1982; 216: 1133-1134.

3. Walterscheid JP, Ullrich SE, Nghiem DX. Platelet-activating factor, a molecular sensor for cellular damage, activates systemic immune suppression. J Exp Med 2002; 195: 171-179.

4. Wolf $P$, Nghiem DX, Walterscheid JP, Byrne S, Matsumura $Y$, Matsumura $Y$ et al. Plateletactivating factor is crucial in psoralen and ultraviolet A-induced immune suppression, inflammation, and apoptosis. Am J Pathol 2006; 169: 795-805.

5. Zhang Q, Yao Y, Konger RL, Sinn AL, Cai S, Pollok KE et al. UVB radiation-mediated inhibition of contact hypersensitivity reactions is dependent on the platelet-activating factor system. J Invest Dermatol 2008; 128: 1780-1787.

6. Benveniste J, Henson P, Cochrane C. Leukocyte-dependent histamine release from rabbit platelets. The role of $\operatorname{lgE}$, basophils, and a platelet-activating factor. J Exp Med 1972; 136: 1356-1377.

7. Lynch JM, Lotner GZ, Betz SJ, Henson PM. The release of a platelet-activating factor by stimulated rabbit neutrophils. J Immunol 1979; 123: 1219-1226.

8. Xu C, Reichert EC, Nakano T, Lohse M, Gardner AA, Revelo MP et al. Deficiency of phospholipase A2 group 7 decreases intestinal polyposis and colon tumorigenesis in Apc (Min/+) mice. Cancer Res 2013; 73: 2806-2816.

9. Camussi G, Aglietta M, Coda R, Bussolino F, Piacibello W, Tetta C. Release of plateletactivating factor (PAF) and histamine. II. The cellular origin of human PAF: monocytes, polymorphonuclear neutrophils and basophils. Immunology 1981; 42: 191-199.

10. O'Donnell M, Fiedel B. Histamine secretion from human leucocytes stimulated by basophil-derived platelet-activating factor. Scand J Immunol 1981; 13: 547-551.

11. Sánchez-Crespo M, Alonso F, Egido J. Platelet-activating factor in anaphylaxis and phagocytosis. I. Release from human peripheral polymorphonuclears and monocytes during the stimulation by ionophore A23187 and phagocytosis but not from degranulating basophils. Immunology 1980; 40: 645-655.

12. Mencia-Huerta J, Benveniste J. Platelet-activating factor (PAF-acether) and macrophages. II. Phagocytosis-associated release of PAF-acether from rat peritoneal macrophages. Cell Immunol 1981; 57: 281-292. 
13. Marathe GK, Johnson C, Billings SD, Southall MD, Pei Y, Spandau D et al. Ultraviolet B radiation generates platelet-activating factor-like phospholipids underlying cutaneous damage. J Biol Chem 2005; 280: 35448-35457.

14. Alappatt C, Johnson CA, Clay KL, Travers JB. Acute keratinocyte damage stimulates platelet-activating factor production. Arch Dermatol Res 2000; 292: 256-259.

15. Byrne SN, Limon-Flores AY, Ullrich SE. Mast cell migration from the skin to the draining lymph nodes upon ultraviolet irradiation represents a key step in the induction of immune suppression. J Immunol 2008; 180: 4648-4655.

16. Chacon-Salinas R, Limon-Flores AY, Chavez-Blanco AD, Gonzalez-Estrada A, Ullrich SE. Mast cell-derived IL-10 suppresses germinal center formation by affecting $T$ follicular helper cell function. J Immunol 2011; 186: 25-31.

17. Sarchio SN, Scolyer RA, Beaugie C, McDonald D, Marsh-Wakefield F, Halliday GM et al. Pharmacologically antagonizing the CXCR4-CXCL12 chemokine pathway with AMD3100 inhibits sunlight-induced skin cancer. J Invest Dermatol 2014; 134: 1091-1100.

18. Chacon-Salinas R, Chen L, Chavez-Blanco AD, Limon-Flores AY, Ma Y, Ullrich SE. An essential role for platelet-activating factor in activating mast cell migration following ultraviolet irradiation. J Leukoc Biol 2014; 95: 139-148.

19. Sreevidya CS, Khaskhely NM, Fukunaga A, Khaskina P, Ullrich SE. Inhibition of photocarcinogenesis by platelet-activating factor or serotonin receptor antagonists. Cancer Res 2008; 68: 3978-3984

20. Sahu RP, Turner MJ, DaSilva SC, Rashid BM, Ocana JA, Perkins SM et al. The environmental stressor ultraviolet $B$ radiation inhibits murine antitumor immunity through its ability to generate platelet-activating factor agonists. Carcinogenesis 2012; 33: 1360-1367.

21. Sreevidya CS, Fukunaga A, Khaskhely NM, Masaki T, Ono R, Nishigori C et al. Agents that reverse UV-Induced immune suppression and photocarcinogenesis affect DNA repair $J$ Invest Dermatol 2010; 130: 1428-1437.

22. Hanahan D, Weinberg RA. Hallmarks of cancer: the next generation. Cell 2011; 144: 646-674.

23. Bussolati B, Biancone L, Cassoni P, Russo S, Rola-Pleszczynski M, Montrucchio G et al. PAF produced by human breast cancer cells promotes migration and proliferation of tumor cells and neo-angiogenesis. Am J Pathol 2000; 157: 1713-1725.

24. Denizot Y, De Armas R, Caire F, Pommepuy I, Truffinet V, Labrousse F. Platelet-activating factor and human meningiomas. Neuropath Appl Neurobiol 2006; 32: 674-678.

25. Denizot Y, Descottes B, Truffinet V, Valleix D, Labrousse F, Mathonnet M. Platelet-activating factor and liver metastasis of colorectal cancer. Int J Cancer 2005; 113: 503-505.

26. Aponte M, Jiang W, Lakkis M, Li MJ, Edwards D, Albitar L et al. Activation of plateletactivating factor receptor and pleiotropic effects on tyrosine phospho-EGFR/Src/FAK/paxillin in ovarian cancer. Cancer Res 2008; 68: 5839-5848.

27. Tsoupras $A B$, latrou $C$, Frangia $C$, Demopoulos $C A$. The implication of platelet activating factor in cancer growth and metastasis: potent beneficial role of PAF-inhibitors and antioxidants. Infect Disord Drug Targets 2009; 9: 390-399.

28. Byrne SN, Sarchio SN. AMD3100 protects from UV-induced skin cancer. Oncoimmunology 2014; 3: e27562.

29. Melnikova V, Bar-Eli M. Inflammation and melanoma growth and metastasis: the role of platelet-activating factor (PAF) and its receptor. Cancer Metastasis Rev 2007; 26: 359-371.

30. Li CJ, Li YZ, Pinto AV, Pardee AB. Potent inhibition of tumor survival in vivo by betalapachone plus taxol: combining drugs imposes different artificial checkpoints. Proc Natl Acad Sci USA 1999; 96: 13369-13374.

31. Ortin I, Gonzalez JF, Cuesta Ede L, Manguan-Garcia C, Perona R, Avendano C. Cytotoxicity mechanisms of pyrazino[1,2-b]isoquinoline-4-ones and SAR studies. Bioor Med Chem 2009, 17: 8040-8047.

32. Spurrier B, Ramalingam S, Nishizuka S. Reverse-phase protein lysate microarrays for cell signaling analysis. Nat Protoc 2008; 3: 1796-1808

33. Daksis JI, Lu RY, Facchini LM, Marhin WW, Penn LJ. Myc induces cyclin D1 expression in the absence of de novo protein synthesis and links mitogen-stimulated signal transduction to the cell cycle. Oncogene 1994; 9: 3635-3645.

34. Travers JB, Li Q, Sprecher H, Fertel RH. Binding of carbamyl-platelet-activating factor to the Raji lymphoblast platelet-activating factor receptor. Int J Immunopharmacol 1992; 14: 515-523.

35. Krempler A, Deckbar D, Jeggo PA, Lobrich M. An imperfect G2M checkpoint contributes to chromosome instability following irradiation of S and G2 phase cells. Cell cycle 2007; 6 : 1682-1686.

36. Norbury C, Blow J, Nurse P. Regulatory phosphorylation of the p34cdc2 protein kinase in vertebrates. EMBO J 1991; 10: 3321-3329.

37. Miike S, Kurasawa K, Saito Y, Iwamoto I. Platelet-activating factor activates mitogenactivated protein kinases through the activation of phosphatidylinositol 3-kinase and tyrosine kinase in human eosinophils. J Leuko Biol 2000; 67: 117-126.

38. Chambard JC, Lefloch R, Pouyssegur J, Lenormand P. ERK implication in cell cycle regulation. Biochim Biophys Acta 2007; 1773: 1299-1310.

39. Waga S, Hannon GJ, Beach D, Stillman B. The p21 inhibitor of cyclin-dependent kinases controls DNA replication by interaction with PCNA. Nature 1994; $369: 574-578$

40. Kapoor M, Lozano G. Functional activation of p53 via phosphorylation following DNA damage by UV but not gamma radiation. Proc Natl Acad Sci USA 1998; 95: 2834-2837.

41. Travers JB, Berry D, Yao Y, Yi Q, Konger RL. Ultraviolet $B$ radiation of human skin generates platelet-activating factor receptor agonists. Photochem Photobiol 2010; 86: 949-954.
42. Hackler PC, Reuss S, Konger RL, Travers JB, Sahu RP. Systemic platelet-activating factor receptor activation augments experimental lung tumor growth and metastasis. Cancer Growth Metastasis 2014; 7: 27-32.

43. Feuerherm AJ, Jorgensen KM, Sommerfelt RM, Eidem LE, Laegreid A, Johansen B. Platelet-activating factor induces proliferation in differentiated keratinocytes. Mol Cell Biochem 2013; 384: 83-94.

44. Porter LA, Donoghue DJ. Cyclin B1 and CDK1: nuclear localization and upstream regulators. Prog Cell Cycle Res 2003; 5 : 335-347.

45. Yu H, Yao X. Cyclin B1: conductor of mitotic symphony orchestra. Cell Res 2008; 18: 218-220.

46. Chesnel F, Bazile F, Pascal A, Kubiak JZ. Cyclin B dissociation from CDK1 precedes its degradation upon MPF inactivation in mitotic extracts of Xenopus laevis embryos. Cell Cycle 2006; 5: 1687-1698.

47. King RW, Jackson PK, Kirschner MW. Mitosis in transition. Cell 1994; 79: 563-571.

48. Wang $\mathrm{H}$, Chakrabarty S. Platelet-activating factor activates mitogen-activated protein kinases, inhibits proliferation, induces differentiation and suppresses the malignant phenotype of human colon carcinoma cells. Oncogene 2003; 22: 2186-2191.

49. Vairapandi M, Balliet AG, Hoffman B, Liebermann DA. GADD45b and GADD45g are cdc2/ cyclinB1 kinase inhibitors with a role in $\mathrm{S}$ and G2/M cell cycle checkpoints induced by genotoxic stress. J Cell Physiol 2002; 192: 327-338.

50. Jin S, Antinore MJ, Lung FD, Dong X, Zhao H, Fan F et al. The GADD45 inhibition of Cdc2 kinase correlates with GADD45-mediated growth suppression. J Biol Chem 2000; 275: 16602-16608.

51. Yang Q, Manicone A, Coursen JD, Linke SP, Nagashima M, Forgues M et al. Identification of a functional domain in a GADD45-mediated G2/M checkpoint. J Biol Chem 2000; 275: 36892-36898.

52. Zhan $Q$, Antinore MJ, Wang XW, Carrier F, Smith ML, Harris CC et al. Association with Cdc2 and inhibition of Cdc2/Cyclin B1 kinase activity by the p53-regulated protein Gadd45. Oncogene 1999; 18: 2892-2900.

53. Wang XW, Zhan Q, Coursen JD, Khan MA, Kontny HU, Yu L et al. GADD45 induction of a G2/M cell cycle checkpoint. Proc Natl Acad Sci USA 1999; 96: 3706-3711.

54. Castedo M, Perfettini JL, Roumier T, Andreau K, Medema R, Kroemer G. Cell death by mitotic catastrophe: a molecular definition. Oncogene 2004; 23: 2825-2837.

55. Lu C, Zhu F, Cho YY, Tang F, Zykova T, Ma WY et al. Cell apoptosis: requirement of H2AX in DNA ladder formation, but not for the activation of caspase-3. Mol Cell 2006; 23: 121-132.

56. Shields BJ, Hauser C, Bukczynska PE, Court NW, Tiganis T. DNA replication stalling attenuates tyrosine kinase signaling to suppress $S$ phase progression. Cancer Cell 2008; 14: 166-179.

57. Saldivar JC, Miuma S, Bene J, Hosseini SA, Shibata H, Sun J et al. Initiation of genome instability and preneoplastic processes through loss of Fhit expression. PLoS Gen 2012; 8: e1003077.

58. Dart DA, Adams KE, Akerman I, Lakin ND. Recruitment of the cell cycle checkpoint kinase ATR to chromatin during S-phase. J Biol Chem 2004; 279: 16433-16440.

59. So S, Davis AJ, Chen DJ. Autophosphorylation at serine 1981 stabilizes ATM at DNA damage sites. J Cell Biol 2009; 187: 977-990.

60. Ananthaswamy HN, Loughlin SM, Cox P, Evans RL, Ullrich SE, Kripke ML. Sunlight and skin cancer: inhibition of p53 mutations in UV-irradiated mouse skin by sunscreens. Nat Med 1997; 3: 510-514

61. Kripke ML, Cox PA, Alas LG, Yarosh DB. Pyrimidine dimers in DNA initiate systemic immunosuppression in UV-irradiated mice. Proc Natl Acad Sci USA 1992; 89: 7516-7520.

62. Butterfield JH, Weiler DA, Hunt LW, Wynn SR, Roche PC. Purification of tryptase from a human mast cell line. J Leukoc Biol 1990; 47: 409-419.

63. Boukamp P, Petrussevska RT, Breitkreutz D, Hornung J, Markham A, Fusenig NE. Normal keratinization in a spontaneously immortalized aneuploid human keratinocyte cell line. J Cell Biol 1988; 106: 761-771.

64. Romano P, Manniello A, Aresu O, Armento M, Cesaro M, Parodi B. Cell Line Data Base: structure and recent improvements towards molecular authentication of human cell lines. Nucleic Acids Res 2009; 37: D925-D932.

65. Ma Y, Hwang RF, Logsdon CD, Ullrich SE. Dynamic mast cell-stromal cell interactions promote growth of pancreatic cancer. Cancer Res 2013; 73: 3927-3937.

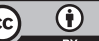

Cell Death and Disease is an open-access journal published by Nature Publishing Group. This work is licensed under a Creative Commons Attribution 4.0 International License. The images or other third party material in this article are included in the article's Creative Commons license, unless indicated otherwise in the credit line; if the material is not included under the Creative Commons license, users will need to obtain permission from the license holder to reproduce the material. To view a copy of this license, visit http://creativecommons.org/licenses/by/4.0/ 